\title{
Genetic characterization of native southern African chicken populations: evaluation and selection of polymorphic microsatellite markers
}

\author{
E. van Marle-Köster ${ }^{1} *$ and L.H. Nel ${ }^{2}$ \\ ${ }^{1}$ Department of Animal and Wildlife Sciences, University of Pretoria, Pretoria, 0002 South Africa \\ ${ }^{2}$ Department of Microbiology and Plant Pathology, University of Pretoria, Pretoria, 0002 South Africa
}

\begin{abstract}
This study presents the first results on the evaluation and selection of polymorphic microsatellite markers for the genetic characterization of native chicken populations in southern Africa. Blood samples for DNA extraction were obtained from five chicken lines from South Africa (Koekoek, New Hampshire, Naked-Neck, Lebowa-Venda and Ovambo), and from one population each from Mozambique and Botswana. Twenty-three markers were found to be polymorphic in most of the lines studied. The mean number of alleles observed for all markers was 6.1, and varied from 2.3 (Koekoek) to 4.3 (Mozambique population). The lowest heterozygosity was found in the Koekoek line (31.4\%), and the highest in the populations from Mozambique (60.7\%) and Botswana (61.2\%). It was concluded that this particular set of microsatellite markers can be of use a measure of genetic variability in native chicken lines in southern Africa, and should be evaluated as diagnostic tools for breed identification.
\end{abstract}

Keywords: native chickens, microsatellite markers, genetic variability.

*Author to whom correspondence should be addressed. E-mail: ekoster@ postino.up.ac.za

\section{Introduction}

Poultry production systems in many developing countries can be classified either as intensive commercial systems or extensive/scavenger systems. The commercial units compare favourably with first-world production standards, and are characterised by environmentally controlled housing, automated feeding and the utilisation of strains selected for high production rates. Despite the increased production of broilers and layers in the developing world, it is estimated that backyard production contributes up to 75\% of eggs and meat produced in Africa, and 50\% of eggs produced in South-Asia (Banarjee \& Sharma, 1998). The fowl found in these backyard or scavenger systems are adapted native or crossbred types that require minimum inputs of feed, housing and management. According to Farrel (1992), 80\% of the chickens in rural systems in China are local breeds. In southern Africa, the native chicken is also associated with low-input systems and household food security. A variety of phenotypically different lines are found in these systems.

The breeding of layer and broiler lines relies on intensive selection and inbreeding, and it can therefore be expected that genetic heterogeneity will be compromised in the long run. During the early 1990's, scientists and livestock producers became particularly concerned about the potential loss of indigenous breeds, and a programme was launched by the FAO for the genetic conservation of poultry resources (Scherf, 1995). Similar projects have since been undertaken for all the major livestock species (Mason \& Crawford, 1993).

To date, native South African chicken lines have received very little scientific attention, and research projects have been directed primarily towards commercial production systems. However, recent changes in agricultural policies emphasising small-scale production and household food security have led to increased appreciation of the roles of these chicken lines in South Africa. During 1994, a programme for the conservation of native chicken lines in South Africa was established at the Poultry Supply Unit of the Animal Improvement Institute (Agricultural Research Council). This population consists of phenotypically different lines, originating from rural areas in the northern and southern parts of South Africa, and from Ovamboland in Namibia. The following chicken lines from the Poultry Supply Unit were included in the study: Koekoek (Figure 1), New Hampshire (Figure 2), Naked-Neck (Figure 3), Lebowa-Venda (Figure 4) and Ovambo (Figure 5).

Although the New Hampshire is not regarded as indigenous, it is also kept as a dual-purpose bird under the same free-range conditions as the other lines. The Koekoek was bred at the former Potchefstroom Agricultural Research Institute during the late forties from a cross between White Leghorn females and Black Austrolorp males. The Plymouth Rock was later introduced to the breeding program. The Koekoek is a dual-purpose breed, and has been kept by farmers and rural dwellers for egg production for household consumption for many years. The Koekoek was accepted as a breed by the South African Poultry Society in 1976 (Viljoen 1986). The origin of the Naked-Neck chicken is disputed, but was probably introduced by early traders from Malaysia on their journeys around the continent 
(J.J. Joubert, 1996; personal communication). A veterinarian working in the area during the seventies first described the Lebowa-Venda fowl, and can be identified by black-and-white or brown-and-white plumage with jade-green feather tips (J.J. Joubert, 1996, personal communication). The Ovambo chicken, a colourful, relatively small but aggressive bird, originated from Ovamboland. No breed standards are presently available for the Naked-neck, Lebowa-Venda or Ovambo chickens. Very little is known about the inter- and intratypic genetic variation among these lines, although decision-making for conservation of these genetic pools would be dependent on such information

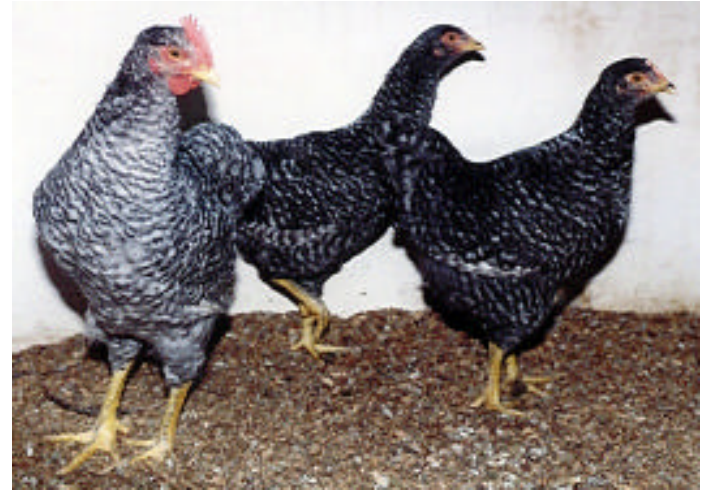

Figure 1 Koekoek fowl: male and female

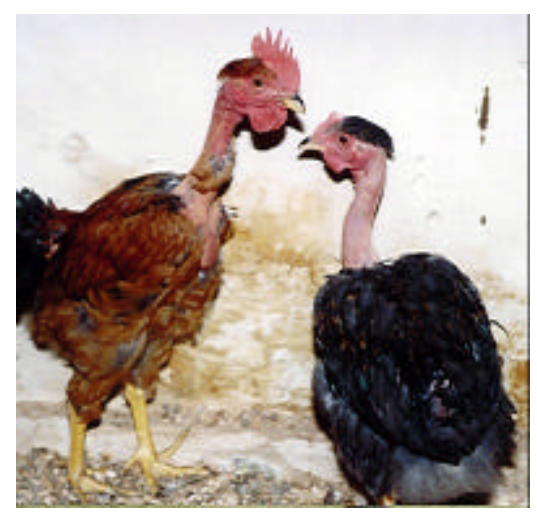

Figure 3 Naked-Neck fowl

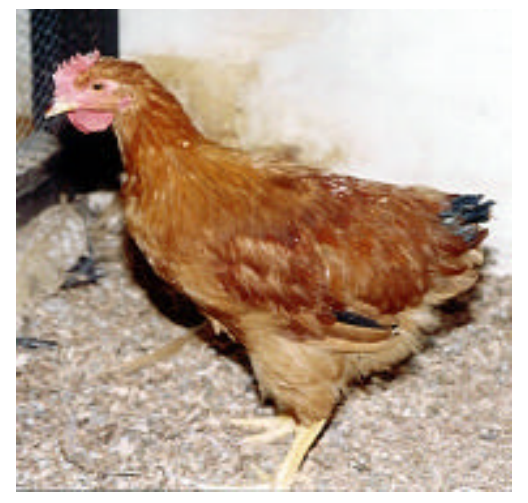

Figure 2 New Hampshire fowl

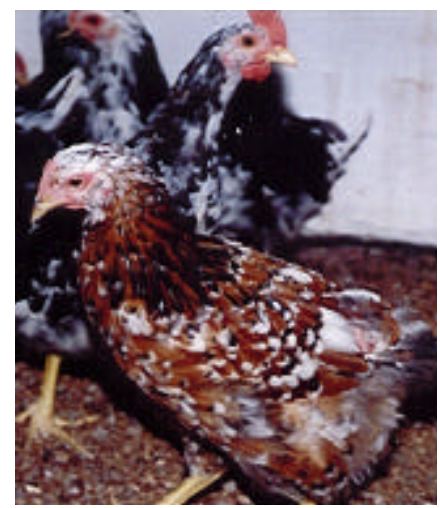

Figure 4 Lebowa-Venda fowl

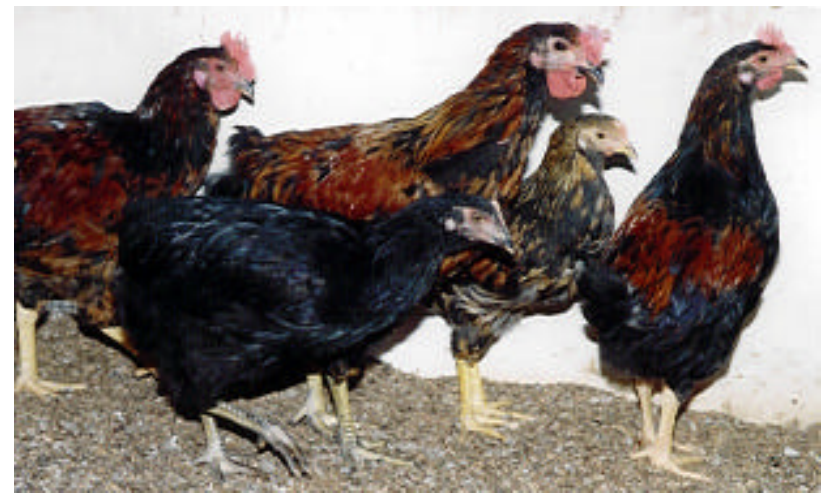

Figure 5 Ovambo fowl 
Microsatellites were described by Tautz (1989) as simple sequence-stretches with a high degree of hypervariability, and are abundant and well distributed in eukaryotic genomes (Cheng \& Crittenden, 1994). These simple sequences consist of short segments of DNA with motif repeats, usually less than six base pairs. Microsatellite markers have been shown to be appropriate tools for linkage mapping, identification of quantitative trait loci and parentage testing (Bruford \& Wayne, 1993). Crooijmans et al. (1996a) and Ponsuksili et al. (1996) also demonstrated the usefulness of microsatellites in the estimation of genetic relatedness and diversity in chickens. Approximately 500 fluorescently labelled primers for microsatellite analysis in chickens have already been described and are commercially available in the form of mapping kits (Cheng et al., 1998). The microsatellites were developed and mapped by the East-Lansing group, Chickmap (Roslin Institute) and Wageningen Agricultural University.

This paper describes the selection and evaluation of a specific set of polymorphic microsatellite markers for measuring the genetic variablity within and between native chicken populations from southern Africa.

\section{Materials and Methods}

Twenty blood samples were collected from each line. Blood samples from native chicken lines found in Botswana and Mozambique were donated by the Botswana Agricultural College and the Eduardo Mondlane University in Mozambique, respectively. Twenty-seven polymorphic microsatellite markers were selected from a collection of markers made available by Dr M. Groenen (Department of Animal Breeding, Wageningen Agricultural University, The Netherlands). Selection was based on the degree of polymorphism and genome coverage (Crooijmans et al., 1996a; M.A.M. Groenen, 1997; personal communication). The characteristics of the markers used are shown in Table 1.

Table 1 Characteristics of microsatellite markers ${ }^{1}$ used for analysis

\begin{tabular}{|c|c|c|c|}
\hline Marker & EL, C, Linkage $^{2}$ & Size Range & Alleles $\mathrm{ASP}^{3}$ \\
\hline MCW 222 & Chromosome 3 & $205-240$ & 3 \\
\hline MCW 330 & E41 & $255-300$ & 4 \\
\hline MCW 183 & Chromosome 7 & $280-320$ & 5 \\
\hline MCW 67 & E29, CO29, W09 & $140-200$ & 3 \\
\hline MCW 98 & Chromosome 4 & $250-270$ & 2 \\
\hline MCW 150 & & $215-250$ & 2 \\
\hline MCW 294 & Chromosome Z & $280-320$ & 3 \\
\hline MCW 295 & Chromosome 4 & $85-120$ & 4 \\
\hline MCW 78 & Chromosome 5 & $130-150$ & 2 \\
\hline ADL 112 & & $120-150$ & 3 \\
\hline LEI 228 & & $160-220$ & \\
\hline LEI 194 & & $120-160$ & 5 \\
\hline MCW 116 & Chromosome 3 & $160-300$ & 2 \\
\hline MCW 206 & Chromosome 2 & $205-250$ & 4 \\
\hline MCW 81 & Chromosome 5 & $105-145$ & 2 \\
\hline ADL 268 & Chromosome 1 & $90-130$ & 4 \\
\hline ADL 278 & E 42 & $100-130$ & 3 \\
\hline MCW 14 & E 11 & $160-190$ & 4 \\
\hline MCW 69 & Unlinked & $145-185$ & 3 \\
\hline MCW 103 & Chromosome 3 & $260-290$ & 2 \\
\hline MCW 111 & Chromosome 1 & $90-120$ & 3 \\
\hline MCW 216 & $\mathrm{E} 48, \mathrm{C} 28$ & $135-165$ & 2 \\
\hline MCW 248 & Chromosome 1 & $205-235$ & 3 \\
\hline
\end{tabular}

${ }^{1}$ Reference: Dr MAM Groenen, 1998. (http://www.zod.wau.nl/vf/research/chicken/body/-infotable.html). ${ }^{2}$ E L, C linkage: mapping results of the marker on the East Lansing and / or Compton reference population (where known). ${ }^{3}$ Alleles ASP: number of alleles observed in the broiler $\mathrm{x}$ broiler cross used to generate the Wageningen Agricultural University linkage map. 
Blood samples were collected in 2-ml tubes containing $80 \mu \mathrm{l}$ EDTA (final concentration: $0.5 \mathrm{M}$ ), and stored at $-70^{\circ} \mathrm{C}$ until analysis. DNA was extracted using a Puregene DNA-isolation kit (Gentra Systems, Minneapolis). DNA concentrations were quantified spectrophotometrically, and samples were diluted to a concentration of $10 \mathrm{ng} / \mu \mathrm{l}$.

PCR reactions were carried out in a volume of $12 \mu$, containing 30-60 ng target DNA, $200 \mu \mathrm{M}$ dNTP's, $1 \mathrm{mM}$ Tetramethylammoniumchloride (TMAC), $10 \mathrm{mM}$ TrisHCl (pH 9.0), $1.5 \mathrm{mM} \mathrm{MgCl}_{2}, 50 \mathrm{mM} \mathrm{KCl}, 0.01 \%$ gelatine, $0.1 \%$ Triton X-100, 0.2 U Goldstar Taq enzyme and 4 pmole of each primer (microsatellite marker). Thermal cycling was carried out with a Thermal Controller (Perkin Elmer) using the following programme: $5 \mathrm{~min}$. at $94^{\circ} \mathrm{C}$ followed by 35 cycles consisting of $30 \mathrm{~s}$. at $94^{\circ} \mathrm{C}, 45 \mathrm{~s}$. at $55^{\circ} \mathrm{C}, 90 \mathrm{~s}$. at $72^{\circ} \mathrm{C}$, and an extension step of $10 \mathrm{~min}$. at $72^{\circ} \mathrm{C}$. The resultant microsatellite amplicons were mixed, and analysed using an automated DNA-sequencer (ABI 373A; Perkin Elmer, Foster City, USA).

\section{Analysis}

Genescan version 2.1 and Genotyper for MacIntosch (PE Biosystems, Foster City, USA) were used to determine the number of alleles per microsatellite marker, and allele frequencies were calculated assuming Hardy-Weinberg equilibrium. Heterozygosity $\left(\mathbf{H}_{\mathbf{1}}\right)$ per microsatellite marker was calculated according to Nei (1987) :

$$
\mathrm{H}_{1} \quad=\quad[2 \mathrm{n} / 2 \mathrm{n}-1]\left[1-\mathrm{iO}^{\mathrm{ml}}\left(\mathrm{pl}_{\mathrm{i}}^{2}\right)\right]
$$

where $\mathrm{n}$ is the number of individual chickens per line, $\mathrm{ml}$ the number of alleles at locus 1 and $\mathrm{pl}_{\mathrm{i}}$ the frequency of the $\mathrm{i}^{\text {th }}$ allele at locus 1 . The standard error was calculated from the total variance at each locus and total variance over all loci studied. Analysis of variance (Tukey's Studentized Range) was used to test for differences in H among lines (SAS, 1992).

\section{Results and Discussion}

The twenty-seven markers selected from the collection made available by the Wageningen Agricultural University (Groenen, 1997) were tested and analysed using 96 DNA samples from the six different chicken lines. Different alleles were detected by 23 of these markers in most of the six lines (Table 2). Most of the markers were polymorphic, detecting more than one allele in all the lines tested. The number of different alleles observed for the microsatellite markers over all the lines varied between two and seventeen. Five microsatellite markers (MCW 222, MCW 294, MCW 14, MCW 103, MCW 248) were found to be monomorphic in the Koekoek. Monomorphism was also detected in the Lebowa-Venda (LEI 194, MCW 116) and in the Botswana lines (MCW 116). The average number of alleles observed for all the markers was 6.1, and varied within line from 2.3 for the Koekoek to 4.3 for the Mozambique line. Groen et al. (1994) obtained similar results in experiments with broilers and layers. In a study with exotic lines (Fayoumi, Dandarawi, Kadakanath), commercial broiler lines and inbred lines (White Leghorn), between two and eleven different alleles were found for the markers (Ponsuksili et al., 1996).

The highest average heterozygosities over all lines were indicated by microsatellite markers MCW 206 (59-72.6\%), ADL 268 (44.3-77.5\%), LEI 228 (50.5-85.8\%) and MCW 295 (54.4-76\%). The lowest average heterozygosity over all lines was indicated by MCW $103(0-54.6 \%)$. The Koekoek line displayed the lowest heterozygosity across all the markers $(31.4 \% ; p=0.001)$. The relatively frequent monomorphisms in several alleles are shown in Table 2 . A high degree of homogeneity is to be expected in the Koekoek, considering that this line was developed from a cross between the Austrolorp, White Leghorn and Plymouth Rock, and was kept as a closed population (Viljoen, 1986). The highest level of heterozygosity across all markers was found in the Mozambique (60.7\%) and Botswana lines (61.2\%), which is in agreement with the diverse phenotypes displayed by these groups of birds. In contrast, no significant differences in the heterozygosity were detected for the New Hampshire, Naked Neck, Ovambo or Lebowa-Venda lines. Using nine microsatellite markers, Vanhala et al. (1998) reported heterozygosity values ranging from $29 \%$ to $67 \%$ in eight chicken lines (three White Leghorn hybrids, three Finish Landrace lines, a Rhode Island Red line and a broiler hybrid line). The highest average heterozygosity for all the markers was found in the broiler line $(67 \%)$. Very low heterozygosity values $(0$ - 10\%) have also been demonstrated by Zhou \& Lamont (1999) using 42 microsatellite markers in a study with inbred chicken lines.

\section{Conclusion}

This paper describes the first attempt to empirically measure and compare the genetic variability in different chicken lines in southern Africa. Genetic variability was shown to correlate with the phenotypic variability associated with the different chicken lines: the lowest genetic variability was found in the Koekoek, a closed population, and the highest variability was detected in the essentially free-ranging lines from Botswana and Mozambique. Results from this study will be used to detect 
population substructures and to develop a set of diagnostic markers for breed identification.

Table 2 Microstellite polymorphism (number of different alleles observed for each microsatellite marker) and percentage heterozygosity for different chicken lines

\begin{tabular}{|c|c|c|c|c|c|c|c|c|}
\hline \multirow[t]{2}{*}{ Marker } & \multicolumn{7}{|c|}{ Line } & \multirow[b]{2}{*}{$\begin{array}{l}\text { Mozamb- } \\
\text { ique }\end{array}$} \\
\hline & $*$ ALL & Koekoek & $\begin{array}{c}\text { New } \\
\text { Hampshire }\end{array}$ & $\begin{array}{l}\text { Naked } \\
\text { Neck }\end{array}$ & $\begin{array}{l}\text { Lebowa } \\
\text {-Venda }\end{array}$ & Ovambo & Botswana & \\
\hline MCW 222 & 4 & 1 & 3 & 3 & 3 & 4 & 4 & 4 \\
\hline MCW 330 & 4 & 3 & 4 & 3 & 3 & 4 & 4 & 4 \\
\hline MCW 183 & 9 & 2 & 3 & 4 & 3 & 6 & 7 & 5 \\
\hline MCW 67 & 5 & 2 & 3 & 3 & 4 & 4 & 3 & 4 \\
\hline MCW 98 & 2 & 2 & 2 & 2 & 2 & 2 & 2 & 2 \\
\hline MCW 150 & 3 & 2 & 2 & 2 & 2 & 2 & 2 & 3 \\
\hline MCW 294 & 8 & 1 & 2 & 2 & 2 & 3 & 7 & 3 \\
\hline MCW 295 & 8 & 3 & 4 & 4 & 4 & 4 & 7 & 5 \\
\hline MCW 78 & 4 & 4 & 2 & 3 & 3 & 3 & 4 & 4 \\
\hline ALD 112 & 4 & 4 & 3 & 3 & 2 & 2 & 3 & 2 \\
\hline LEI 228 & 17 & 3 & 7 & 6 & 3 & 5 & 9 & 10 \\
\hline LEI 194 & 9 & 3 & 4 & 4 & 1 & 4 & 5 & 7 \\
\hline MCW 116 & 3 & 2 & 2 & 3 & 1 & 2 & 1 & 2 \\
\hline MCW 206 & 11 & 4 & 4 & 4 & 5 & 4 & 4 & 7 \\
\hline MCW 81 & 6 & 4 & 3 & 4 & 3 & 4 & 5 & 5 \\
\hline ADL 268 & 7 & 2 & 5 & 3 & 4 & 5 & 5 & 5 \\
\hline ADL 278 & 3 & 3 & 3 & 3 & 3 & 3 & 3 & 3 \\
\hline MCW 14 & 4 & 1 & 3 & 3 & 2 & 2 & 3 & 3 \\
\hline MCW 69 & 9 & 2 & 4 & 2 & 2 & 3 & 6 & 6 \\
\hline MCW 103 & 3 & 1 & 2 & 2 & 2 & 2 & 3 & 3 \\
\hline MCW 111 & 8 & 3 & 3 & 3 & 4 & 2 & 6 & 5 \\
\hline MCW 216 & 7 & 2 & 3 & 4 & 3 & 3 & 4 & 4 \\
\hline MCW 248 & 4 & 1 & 4 & 4 & 3 & 3 & 3 & 4 \\
\hline Mean & 6.1 & 2.3 & 3.2 & 3.2 & 2.7 & 3.3 & 4.3 & 4.3 \\
\hline $\begin{array}{l}\text { Heterozygos } \\
(\text { mean \%) }\end{array}$ & - & 31.4 & 51.5 & 54.7 & 42.8 & 53.1 & 61.2 & 60.7 \\
\hline S.E. & - & \pm 2.57 & \pm 3.82 & \pm 3.55 & \pm 3.07 & \pm 3.87 & \pm 3.78 & \pm 4.21 \\
\hline
\end{tabular}

*All: different alleles per marker across all lines 


\section{References}

Banarjee, A.K. \& Sharma, R.K., 1998. Breeding possibilities in adverse climatic conditions with special reference to Indian conditions. Proc. $10^{\text {th }}$ European Poultry Conference, Jerusalem, Israel. pp. 505-508.

Bruford, M.W. \& Wayne, R.K., 1993. Microsatellites and their application to population genetic studies. Current opinion in genetics and development. 3: 939-943.

Cheng, H.H., Burt, D.W. \& Dodgson, J.B., 1998. Recent advances in poultry genome mapping. Proc. Symposium Series 1 of the 8th World Conference on Animal Production. Seoul National University, Seoul, Korea. pp. 168-178.

Cheng, H.H. \& Crittenden, L.B., 1994. Microsatellite markers for genetic mapping in the chicken. Poultry Sci. 73: 539-546.

Crooijmans, R.P.M.A., Groen, A.B.F., Van Kampen, A.J.A., Van Der Beek, S., Van Der Poel, J.J., Groenen, M.A.M., 1996a. Microsatellite polymorphism in commercial broiler and layer lines estimated using pooled blood samples. Poultry Sci. 75: 904-909.

Crooijmans, R.P.M.A., Van Oers, P.A.M., Strijk, J.A., Van Der Poel, J.J., Groenen, M.A.M., 1996b. Preliminary linkage map of the chicken (Gallus domesticus) genome based on microsatellite markers: 77 New Markers Mapped. Poultry Sci. 75: 746-752.

Farrel, D.J., 1992. The problems of assisting the poultry industry in the third world, where do we go wrong? Proc. XIV World Poultry Congress, Amsterdam. 3: 706-709.

Groen, A.F., Crooijmans, R.P.M.A, Van Kampen, A.J.A., Van Der Beek, S., Van Der Poel, J.J., Groenen, M.A.M., 1994. Microsatellite polymorphism in commercial broilers and layers. Proc. 5th Wld. Symp. Gen. Appl. Livestock Production, Guelph. 21: 94-97.

Mason, I.L. \& Crawford, R .D., 1993. Global status of livestock and poultry species. In: Managing Global Livestock Resources. NRC Washington, National Academy Press, Washington DC. pp. 140-165.

Nei, M., 1987. Molecular evolutionary genetics. Columbia University Press, New York.

Ponsuksili, S., Wimmers, K. \& Horst, P., 1996. Genetic variability in chickens using polymorphic microsatellite markers. Thai J. Agric. Sci. 29: 571-580.

SAS, 1992. SAS Institute Inc. SAS/STAT users guide. NC-SAS Institute Inc., Cary, USA.

Scherf, B.D., 1995. Developing the global inventory for poultry genetic resources. In: Proc. Third Global Conference on Conservation of Domestic Animal Genetic Resources. Queens University, Canada. pp. 81-93.

Tautz, D., 1989. Hypervariability of simple sequences as a general source for polymoorphic DNA markers. Nucleic Acids Res. 17: 6463-6471.

Vanhala, T., Tuiskula-Haavisto, M., Elo, K., Vilkki, J. \& Mäki-Tanil, A.A., 1998. Evaluation of genetic variability and genetic distances between eight chicken lines using microsatellite markers. Poultry Sci. 77: 783-790.

Viljoen, W.C.J., 1986. Hoenderrasse - pluimvee. In: Boerdery in Suid Afrika, Pamphlet A2/1979. Department of agriculture and water supply, Pretoria.

Zhou, H. \& Lamont, S.J., 1999. Genetic characterization of biodiversity in highly inbred chicken lines by microsatellite markers. Anim. Gen. 30: 256-264. 